\title{
Processing and Performance Evaluation of Amine Functionalized Graphene Nanoplatelet Reinforced Epoxy Composites
}

\author{
Mohammad K. Hossain ${ }^{1 *}$, Md Mahmudur R. Chowdhury ${ }^{1}$ and Nydeia W Bolden ${ }^{2}$ \\ 1. Department of Mechanical Engineering, Tuskegee University, Tuskegee, AL 36088, USA \\ 2. Air Force Research Laboratory Munitions Directorate, Eglin AFB, FL 32542, USA
}

\begin{abstract}
A systematic study was conducted on processing and characterization of epoxy-EPON 828 polymer composite to enhance its mechanical, viscoelastic, and thermal properties through the integration of an optimum amount of amine-functionalized graphene nanoplatelets (GNP). Amine functionalized 0.1, 0.2, 0.3, 0.4 and $0.5 \mathrm{wt} \%$ GNP was infused into EPON 828 Part-A using a high intensity ultrasonic liquid processor followed by three roll milling. The Epoxy-GNP mixture was then mixed with the curing agent Epikure 3223. The mixture was then placed in a vacuum oven at $40{ }^{\circ} \mathrm{C}$ for 10 minutes. The as-prepared resin mixture was then poured in rubber molds to prepare samples for characterization according to ASTM standards. Simultaneously, neat epoxy samples were fabricated to obtain its baseline properties. The mechanical properties were determined through flexure test and the fracture morphology was evaluated through scanning electron microscopy (SEM). Dynamic mechanical analysis (DMA) and thermomechanical analysis (TMA) were performed to analyze viscoelastic and thermomechanical properties to determine thermal performances. The results indicate that the $0.4 \mathrm{wt} \%$ GNP infused epoxy nanocomposite exhibited the best properties. The tests showed $20 \%$ and $40 \%$ improvement in flexure strength and modulus, respectively. SEM micrographs exhibited smooth fracture surface for the neat sample. The roughness of fracture surfaces increased as more GNP was added to the composites. Moreover, $16 \%$ improvement in the storage modulus and $37 \%$ decrease in the coefficient of thermal expansion were observed.
\end{abstract}

Key words: Graphene nanoplatele, mechanical properties, viscoelastic properties, amino functionalized, DMA (Dynamic mechanical analysis), TMA (Thermomechanical analysis).

\section{Introduction}

Scientists have been engaged in developing polymer matrix and fiber reinforced polymer (FRP) matrix composites that possess enhanced mechanical, thermal, and electrical properties to use in the field of aviation, automotive, naval, structural, and recreational sport industries. In last two decades, researchers have successfully enhanced polymer matrix properties by incorporating various nanoparticles such as nanoclay, carbon nanofibers (CNF), carbon nanotubes (CNT), and silicon carbide. Among them CNT has been proven to be the best candidate for matrix modification because of its

\footnotetext{
*Corresponding author: Mohammad K. Hossain, Ph.D., research fields: materials and design.
}

exceptional strength and stiffness, high specific surface area, and high aspect ratio [1-3]. However, due to higher production cost of CNT [2] the mass production of CNT based multifunctional composites is also expensive.

The graphene nanoplatelet (GNP) having a two dimensional planar structure is composed of several layers of graphite nanocrystals stacked together $[4,5]$ with an ultrahigh aspect ratio. The GNP is thus able to provide excellent reinforcement and thermal conducting abilities along with improved mechanical and thermal properties. The GNP is considered to be a novel nanofiller due to its exceptional functionalities, high mechanical strength, chemical stability, abundance in nature, and cost effectiveness. The GNP provides large specific surface area which transfers a 
large amount of stress across the interface and provides higher reinforcement than CNT. When an optimum amount of GNP is added into polymer, it becomes electrically and thermally conductive. Also its mechanical properties including strength, stiffness, and surface toughness improve. The GNP is useful in the field of advanced composites as nanofillers, batteries, ultra/super capacitors, exceptionally strong and impermeable packaging, lubricants, and highly sensitive bio-sensors. Superior properties of graphene as fillers are observed in polymer/graphene nanocomposites [6-9]. Compared to the mechanical and electrical properties of clay or other carbon-filler based polymer nanocomposites, graphene based polymer nanocomposites exhibit better properties $[10$, 11]. In terms of thermal and electrical conductivity, the graphene behaves as a better nanofiller than the CNT [12-14]. An improvement of fracture toughness of epoxy from $0.97 \mathrm{MPa} \sqrt{ } \mathrm{m}$ to $1.48 \mathrm{MPa} \sqrt{ } \mathrm{m}$ at 0.1 $w t \%$ filler fraction was found in one study [15]. Investigating the graphene epoxy composites at low filler content of $0.1 \mathrm{wt} \%$ showed a significant increase of $31 \%$ in modulus and $40 \%$ in fracture toughness [16]. In another study a method was proposed to prepare epoxy/graphite nanocomposites by mixing epoxy with graphite in solvent [17]. This demonstrated that use of $4 \mathrm{wt} \%$ graphite causes Young's modulus to be increased by $10 \%$ and glass transition temperature $\left(\mathrm{T}_{\mathrm{g}}\right)$ from $143{ }^{\circ} \mathrm{C}$ to $145^{\circ} \mathrm{C}$.

The surface modification of nanofillers helps rejuvenate the interaction between the matrix and nanofillers ensuing better dispersion quality and high performances [18]. Better overall properties and enhanced interfaces between two components of the polymer matrix can be obtained by applying modification through chemical bonding [19, 20]. Amino functionalization of the CNT has been extensively used to improve interfacial interaction with epoxy matrices [21-23]. Functionalization is the fundamental process of introducing new functions or properties to a material by changing the surface chemistry of that material. This is performed by attaching molecules or nanoparticles on the surface of a material through chemical bonding as well as adsorption. The basic applications of surface functionalization range from altering the wetting or adhesion characteristics and improving the nanoparticle dispersion in matrices to enhancing the catalytic properties and ordering the interfacial region.

There have been several studies on mechanical and thermal behavior of exfoliated GNP reinforced polymeric composites. Addition of a small amount of GNP improved electrical [24, 25], thermal [26, 27], and mechanical properties significantly [28-30]. Thermal stability and flammability of polymer composites were also improved [31-33]. However, to the best of authors' knowledge, no study has been reported in the open literature on the effect of amino functionalized GNP on mechanical, viscoelastic, and thermal properties of epoxy nanocomposites. The wide range of attractive properties and increasing use of these nanophased composites in important areas of industries and the insufficient data in the relevant field have led the authors to select this research project. The objective of this study is to process and characterize the epoxy-GNP nanocomposite with the integration of an optimum amount of amine functionalized GNP to enhance mechanical, viscoelastic, and thermal properties of the epoxy polymer composite.

In this study, amino functionalized GNP reinforced epoxy nanocomposites were manufactured using the combination of sonication and the 3 roll mixing process. Flexure test, DMA, and TMA, were performed to investigate the effect of GNP on mechanical, viscoelastic, and thermomechanical properties of the Epoxy-GNP nanocomposite.

\section{Experimental}

\subsection{Materials}

The matrix used in this study is a two part system manufactured by Miller Stephenson Chemical 
Company, USA. Part A is EPON 828, Diglycidyl Ether of Bisphenol A (DGEBA) which is a low viscosity liquid epoxy resin. Part B is Epikure 3223, a Diethylenetriamine (DETA) which is used as a curing agent of epoxy resin. The GNP functionalized with amine groups $\left(-\mathrm{NH}_{2}\right)$ was received from Cheap Tubes Inc., Vermont, USA. The GNP consists of small stacks of graphene. The GNP had an average thickness less than $5 \mathrm{~nm}$ and specific surface area about $700 \mathrm{~m}^{2} / \mathrm{g}$. The GNP was covalently functionalized by amine $\left(-\mathrm{NH}_{2}\right)$ in order to achieve the required exfoliation and dispersion. The concentration of functional groups was less than $7 \%$.

\subsection{Nanocomposite Processing}

First, pre-calculated amount of GNP $(0.1,0.20 .3$, 0.4 or $0.5 \mathrm{wt} \%$ ) was mechanically mixed with epoxy resin Part-A by a mechanical stirrer for 4-5 minutes . The mixture was then put into a sonicator for 1 hour at $35 \%$ amplitude and $40 \mathrm{~s}$ on/ $20 \mathrm{~s}$ off cycle pulse mode. To avoid premature polymerization, this mixture was drowned thoroughly in a cooling bath. The sonicated mixture was then passed through three rollers to further improve the dispersion of GNP. In this process, The GNP was further de-agglomerated and uniformly dispersed in resin by the induction of a high shear force in the mixture. The gap space was incrementally reduced from 20 to $5 \mu \mathrm{m}$ between the rolls and multiple passes were used. The speed ratio of the three rollers was 1:3:9 with a maximum speed of $140 \mathrm{rpm}$. The Epoxy-GNP mixture was then mixed with the curing agent Epikure 3223 according to the stoichiometric ratio (Part A: Part $\mathrm{B}=12: 1$ ). The mixture was then placed in a vacuum oven at $40{ }^{\circ} \mathrm{C}$ for 10 minutes to ensure the complete removal of entrapped bubbles and thus reduce the chance of void formation. The prepared resin mixture was then poured in a rubber mold to prepare the samples for characterization according to ASTM standards.

\subsection{Material Characterization}

\subsubsection{Flexure Test}

Flexural test under three-point bend configuration was performed on a Zwick Roell testing unit according to the ASTM D790-02 standard. The sample size was $52 \mathrm{~mm} \times 12.25 \mathrm{~mm} \times 3.2 \mathrm{~mm}$ to maintain a span to thickness ratio of 16:1. The machine was run under displacement control mode at a crosshead speed of $2.0 \mathrm{~mm} / \mathrm{min}$ at room temperature. A minimum of five samples of each category were tested.

\subsubsection{Fracture Morphology Study}

Fracture morphological properties of composite samples were evaluated through SEM study using a Zeiss EVO 50. SEM samples were positioned on a sample holder with a silver paint and coated with gold by a low vacuum sputtering machine prior to loading in the SEM to prevent charge build-up by the electrons absorbed by the specimen. A $20 \mathrm{KV}$ accelerating voltage was applied to achieve desired magnification.

\subsubsection{Dynamic Mechanical Analysis (DMA)}

DMA was performed with a TA Instruments dynamic mechanical analyzer (Model Q800) according to the ASTM D4065-01 standard under a dual cantilever beam mode with a frequency of $1 \mathrm{~Hz}$ and an amplitude of $15 \mu \mathrm{m}$. The temperature was ramped from $30{ }^{\circ} \mathrm{C}$ to $200{ }^{\circ} \mathrm{C}$ at a rate of $10{ }^{\circ} \mathrm{C} / \mathrm{min}$. A minimum of five samples of each category were tested.

\subsubsection{Thermomechanical Analysis (TMA)}

TMA tests were carried out on a TA instruments thermomechanical analyzer (Model Q400) operating in an expansion mode at a heating rate of $10{ }^{\circ} \mathrm{C} / \mathrm{min}$ from $30{ }^{\circ} \mathrm{C}$ to $200{ }^{\circ} \mathrm{C}$. Five samples of each type were tested, and the CTE for each of those samples was determined before the glass transition temperature. 


\section{Results and Discussions}

\subsection{Flexural Properties}

The stress-strain behavior of neat and nanophased composites is presented in Fig. 1. Significant non-linearity can be observed in all stress strain curves. Due to higher aspect ratio and specific surface area of GNP, they can effectively inhibit crack generation and crack propagation in the matrix and thus contribute in enhancing the stiffness and strength of nanophased composites. The positive reinforcing effect of GNP addition is evident from Fig. 1. Flexural modulus and strength were enhanced by $40 \%$ and $20 \%$, respectively, in the $0.4 \mathrm{wt} \%$ GNP-loaded sample compared to those of the conventional one. Since the GNP consisted of layered structures, proper exfoliation and uniform dispersion of GNP in resin are important to enhance the properties of nanocomposites, which were attained in this study by the combination of sonication and three roll mixer.

The amine functional groups of GNP and the epoxide groups of DGEBA resin when mixed together facilitate ring opening reactions followed by crosslinking [21]. This crosslinking creates an interlocking structure in the resin blend through the covalent bond, which results in impediment in the mobility of polymer chains in the system. Interfacial interaction facilitates stress transfer during loading and thus results in an increase in flexural properties [34] up to $0.4 \mathrm{wt} \%$ loading. However, a slight drop in flexural strength and flexural modulus were observed for the $0.5 \mathrm{wt} \%$ loading of the GNP. This drop in flexure strength and modulus is attributed to the formation of excessive agglomeration. These agglomerates act as stress risers and also increase the free volume by creating voids in the matrix [35]. The resultant data of flexure tests are presented in Table 1.

\subsection{Fracture Morphology Study}

Fig. 2 shows the SEM micrographs of neat and nanophased fractured surfaces of composites obtained from the three point bending test. Scanning electron microscopic images were obtained from the fractured surface to observe the fracture mode at a higher magnification. The fracture surface of neat epoxy was notably smooth. In Fig. $2 \mathrm{a}$, it can be observed that the resin crack originated away from any interruption. When epoxy resin was reinforced with nanoparticles,

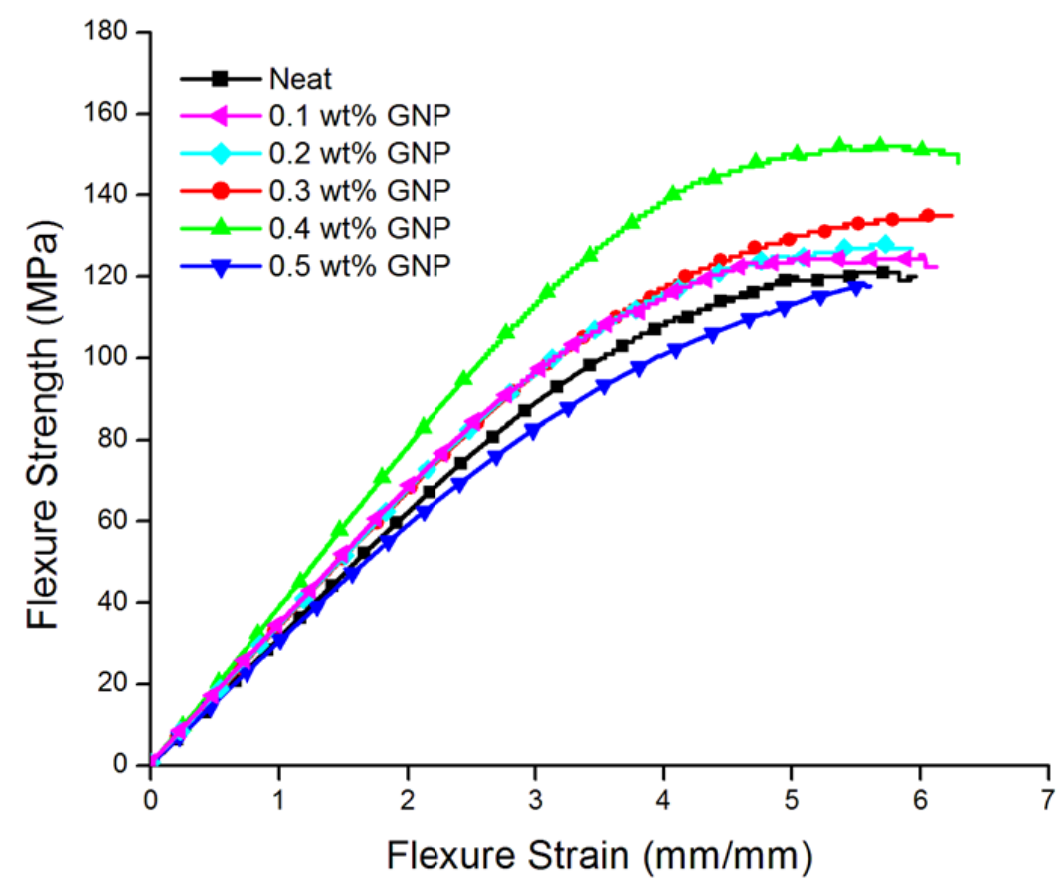

Fig. 1 Flexural stress vs. strain response of control and GNP reinfroced epoxy samples. 
Table 1 Flexure test results of control and GNP reinfroced epoxy samples.

\begin{tabular}{lllllll}
\hline \multirow{2}{*}{ Properties } & \multicolumn{5}{c}{ Sample specification } \\
\cline { 2 - 7 } & Neat & $0.1 \mathrm{wt} \%$ & $0.2 \mathrm{wt} \%$ & $0.3 \mathrm{wt} \%$ & $0.4 \mathrm{wt} \%$ & $0.5 \mathrm{wt} \%$ \\
\hline Flexural strength (MPa) & $124.95 \pm 2.41$ & $130.70 \pm 1.87$ & $131.76 \pm 1.36$ & $135.30 \pm 1.80$ & $150.37 \pm 8.17$ & $118.54 \pm 5.06$ \\
Difference with neat (\%) & - & +4.6 & +5.45 & +8.28 & +20.34 & -5.1 \\
Flexure modulus (GPa) & $3.17 \pm 0.16$ & $3.28 \pm 0.19$ & $3.33 \pm 0.11$ & $3.44 \pm 0.10$ & $4.45 \pm 0.68$ & $2.83 \pm 0.13$ \\
Difference with neat (\%) & - & +3.47 & +5.04 & +5.36 & +40.37 & -10.72 \\
\hline
\end{tabular}

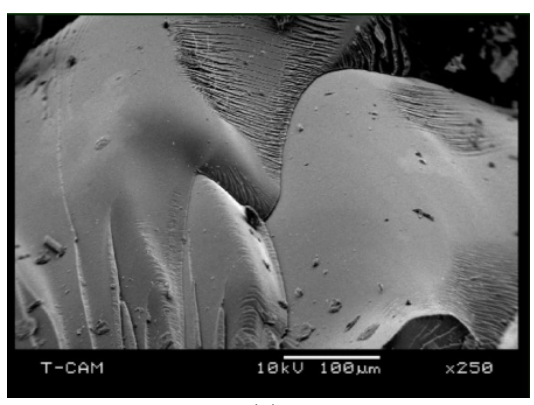

(a)

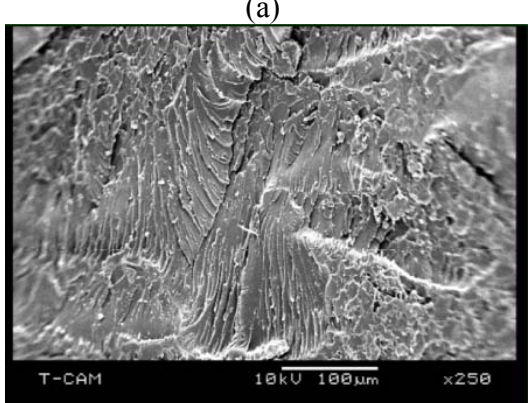

(d)

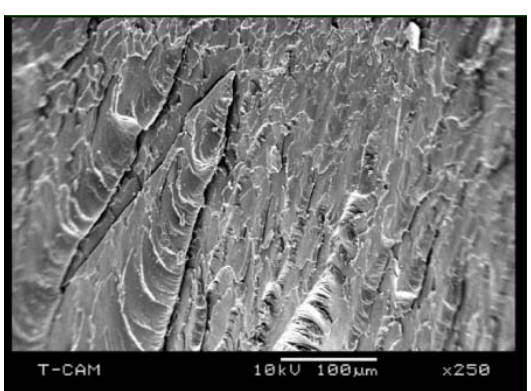

(b)

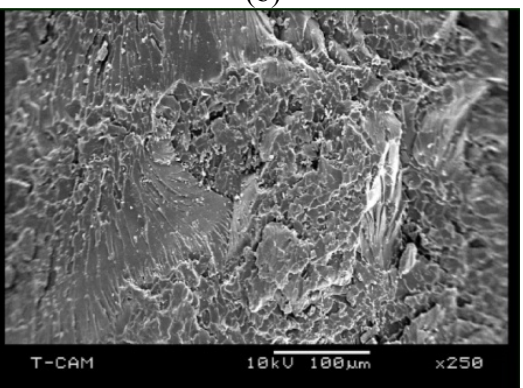

(e)

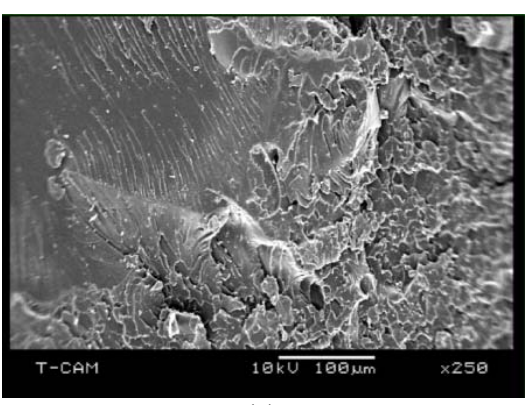

(c)

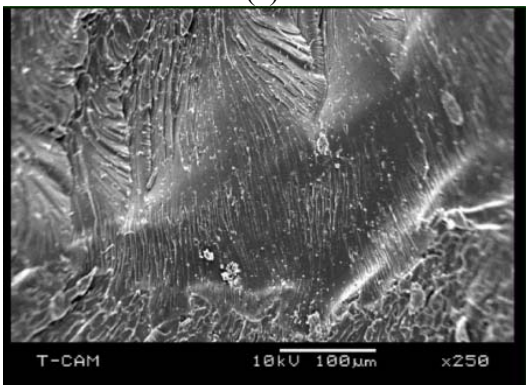

(f)

Fig. 2 SEM images of fracture surface of (a) neat, (b) $0.1 \mathrm{wt} \%$, (c) $0.2 \mathrm{wt} \%$, (d) $0.3 \mathrm{wt} \%$, (e) $0.4 \mathrm{wt} \%$ and (f) $0.5 \mathrm{wt} \%$ GNP/epoxy cpmposites.

infused nanoparticles obstructed the propagation of cracks in nanocomposites. Thus, crack propagation was significantly hindered in nanoparticle reinforced composites as they have to change directions when the crack encountered nanoparticles. Moreover, nanoparticle pullout occurred during the crack propagation requiring high energy dissipation. In Figs. 2b-2f from the SEM micrographs of fractured surfaces, it can be seen clearly that the nanoparticle pullout left a rough surface. Nanophased samples also showed much rougher surfaces due to the strong interfacial interaction of the GNP with epoxy compared to the neat one. Presence of small agglomerates was evident in the $0.5 \mathrm{wt} \%$ sample (Fig. 2f). On the other hand, uniform dispersion of the GNP was observed for $0.1,0.2,0.3$ and $0.4 \mathrm{wt} \%$ samples.

\subsection{Dynamic Mechanical Analysis (DMA)}

Dynamic mechanical analysis provides the viscoelastic properties such as storage modulus, loss modulus and $\tan \delta$ of composite samples as a function of temperature. The amount of energy stored in the composite after deformation is represented by the storage modulus. Storage modulus of a composite is determined by keeping the specimen under a cyclic loading at elevated temperatures while performing the dynamic mechanical analysis test.

The variation of storage modulus is presented in Fig. 3 as a function of temperature $\left(30-200{ }^{\circ} \mathrm{C}\right)$ for different percentages of GNP nanofiller concentration. It is clear from the figure that there was an increase in storage modulus due to the addition of nanoparticles in almost all temperature regions. 


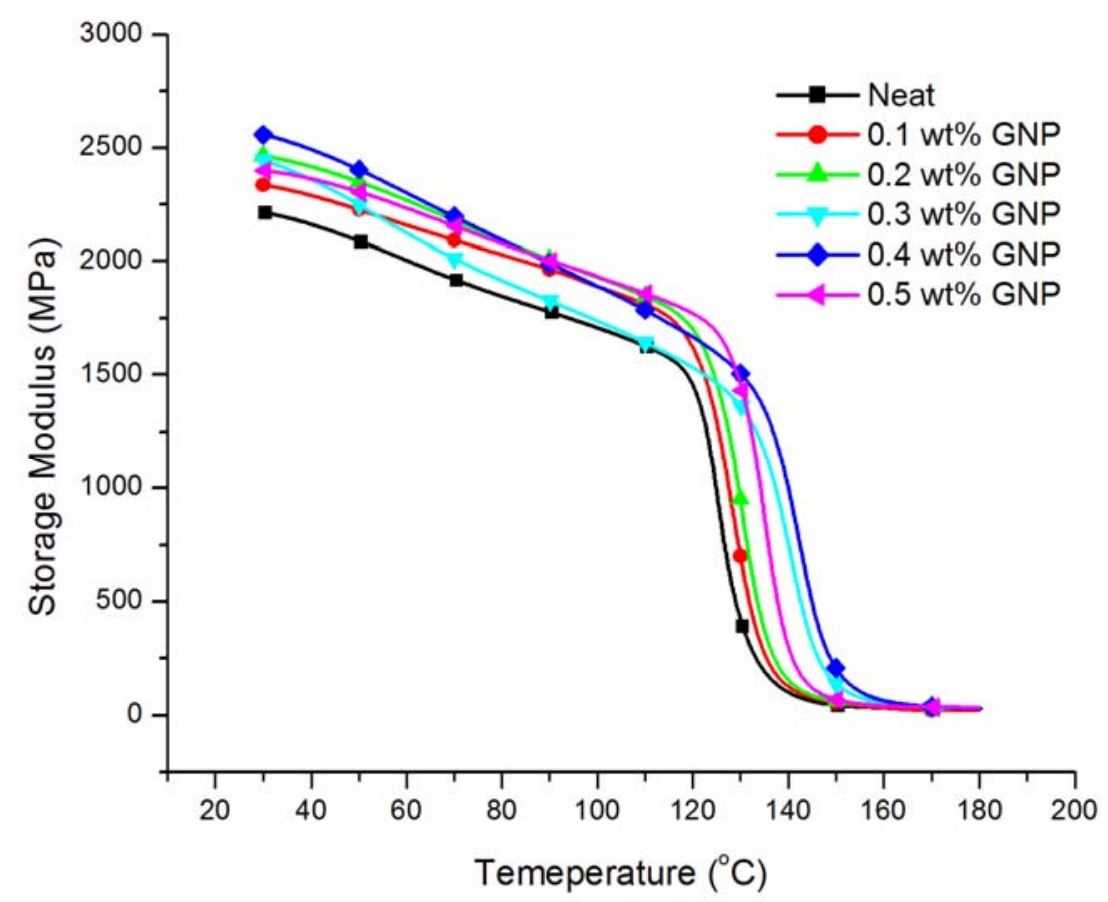

Fig. 3 Storage modulus of GNP reinforced and control epoxy nanocomposites.

In Fig. 3, the sharp drop in storage modulus indicates the glass transition temperature $\left(\mathrm{T}_{\mathrm{g}}\right)$ of the composite. The entire region can be divided into two sections: below $\mathrm{T}_{\mathrm{g}}$ (glassy plateau region) and above $\mathrm{T}_{\mathrm{g}}$ (rubbery plateau region). The operating temperature of the composite should be below $T_{g}$. Viscoelastic properties increase significantly with the addition of GNP concentration up to the $0.4 \mathrm{wt} \%$. Storage modulus was improved gradually with the addition of the GNP and the maximum improvement of $16 \%$ was observed in the $0.4 \mathrm{wt} \%$ loaded GNP sample at $30{ }^{\circ} \mathrm{C}$. Enhanced interaction between well dispersed nanofillers and matrix has aided this improvement. A schematic representation of interfacial reaction between DGEBA and GNP-NH $\mathrm{N}_{2}$ are shown in Fig.4.

The formation of a strong covalent bond shown in Fig. 4 is due to the presence of amino functional groups of GNP and its reaction with epoxy. Self-crosslinks are formed by hydrogen atoms in amine groups of DETA molecule (hardener) with each other by reacting with epoxide groups of DGEBA in control epoxy samples. From Fig. 4 it is evident that, in case of nanophased samples, the interfacial reaction between amine functional groups of GNP and epoxide groups of DGEBA resin occurs at first by ring opening reaction after EPON 828 (Part A) and GNP-NH $\mathrm{N}_{2}$ were mixed. This modified Part-A establishes a strong covalent bond between the epoxy and the GNP upon further mixing with Part-B of epoxy resin boosting crosslinking sites and interfacial bonding. Formation of covalent bond and the enhanced reaction make it possible to abridge the epoxy chain molecular motion around GNP. This abridgement results in a significant change of elastic and viscous properties in nanocomposites. Moreover, the exfoliation of layered structure of GNP strengthens the resin. Thus, the enhancement of storage modulus can be attributed to the functionalization and uniform dispersion of nanoparticles in the nanocomposite. The covalent bond between the epoxy and the GNP is a major factor in the improvement of thermomechanical properties.

Loss modulus indicates the energy dissipated into heat when any deformation occurred under load. Under cyclic loading, it is the unrecoverable dissipated 


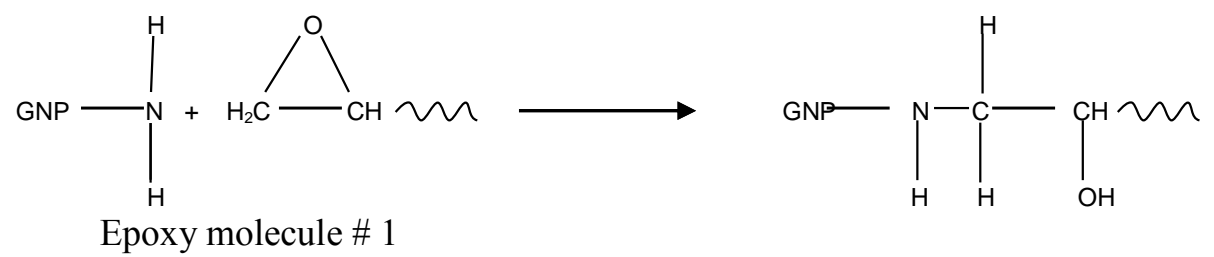

(a)

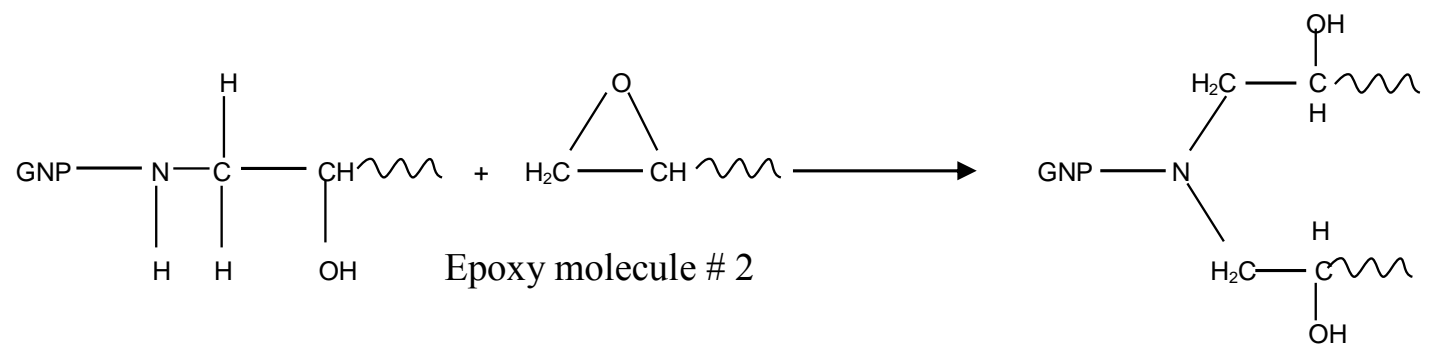

(b)
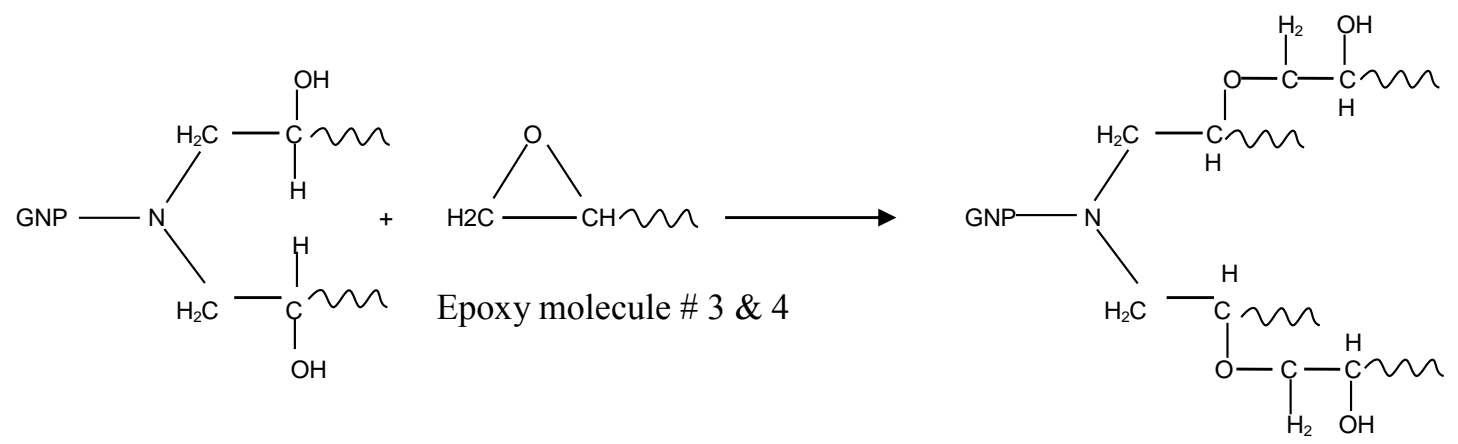

(c)

Fig. 4 Schematic representation of interfacial reaction between DGEBA and GNP-NH $\mathrm{N}_{2}$ : (a) reaction of epoxide group (DGEBA) with primary amine of functionalized GNP, (b) reaction of epoxide group (DGEBA) with primary amine of functionalized GNP and (c) cross-linking reaction between epoxy and GNP.

energy per cycle. Fig. 5 illustrates the loss modulus for unmodified and GNP-loaded modified composite samples.

It can be seen from Fig. 5 that the loss modulus increases with the increase in temperature up to the glass transition temperature and decreases after that for all composite samples. The temperature that is associated with the peak of loss modulus represents the glass transition temperature. For the $0.4 \mathrm{wt} \%$ GNP modified composite, loss modulus is the highest. High resistance against the movement of surrounding matrix is due to the uniform distribution of nanofillers. This results in a high dissipation of energy [34]. In addition, exfoliation of GNP allows the resin to reside in graphene layers. This allows strengthening of the matrix. Hence, more energy dissipation occurs in case of the GNP reinforced composites compared to the composites without nanofiller during the deformation process. The variation in storage and loss modulus is presented in Fig. 6 for the neat as well as 0.1 to $0.5 \mathrm{wt} \%$ GNP-loaded samples.

The $\tan$-delta $(\tan \delta)$ vs temperature relationship in Fig. 7 illustrates the effect of GNP concentration on damping properties of nanocomposite. Tan-delta $(\tan \delta)$ values are derived from the ratio of loss modulus over storage modulus. The glass transition temperature 


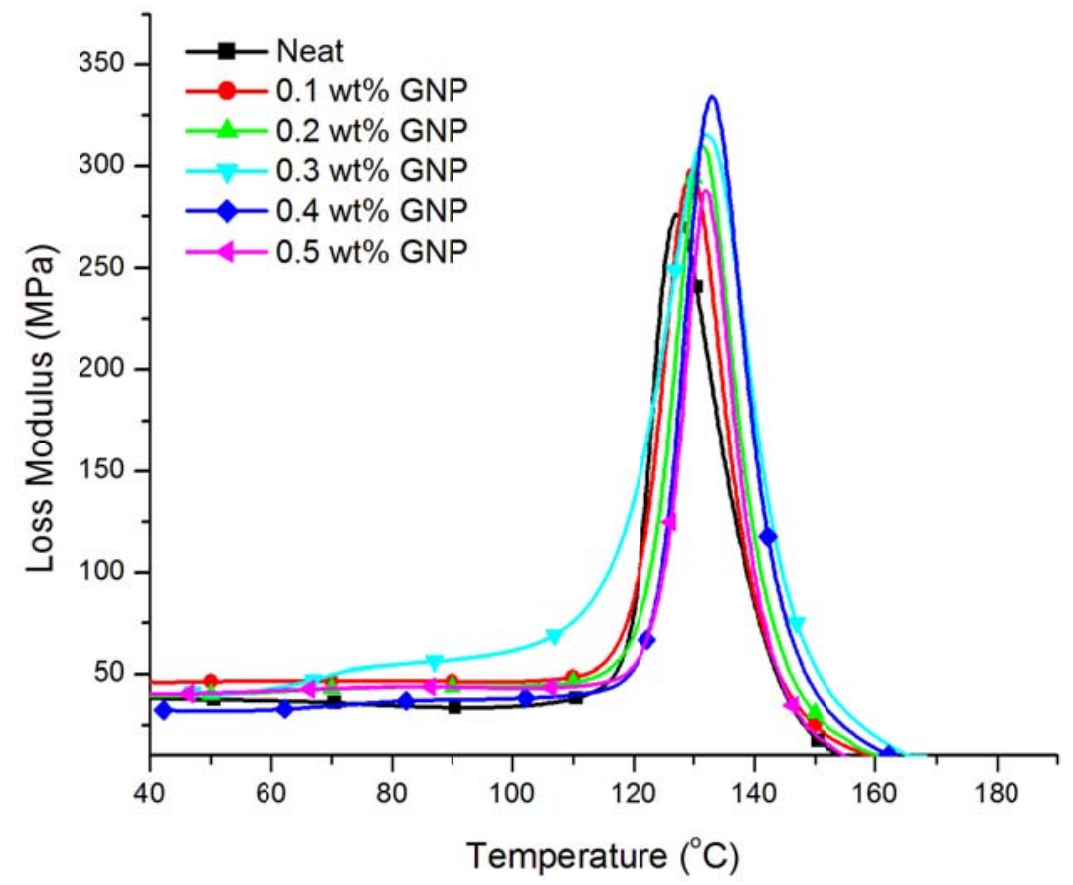

Fig. 5 Loss modulus of control and GNP reinforced epoxy nanocomposites.

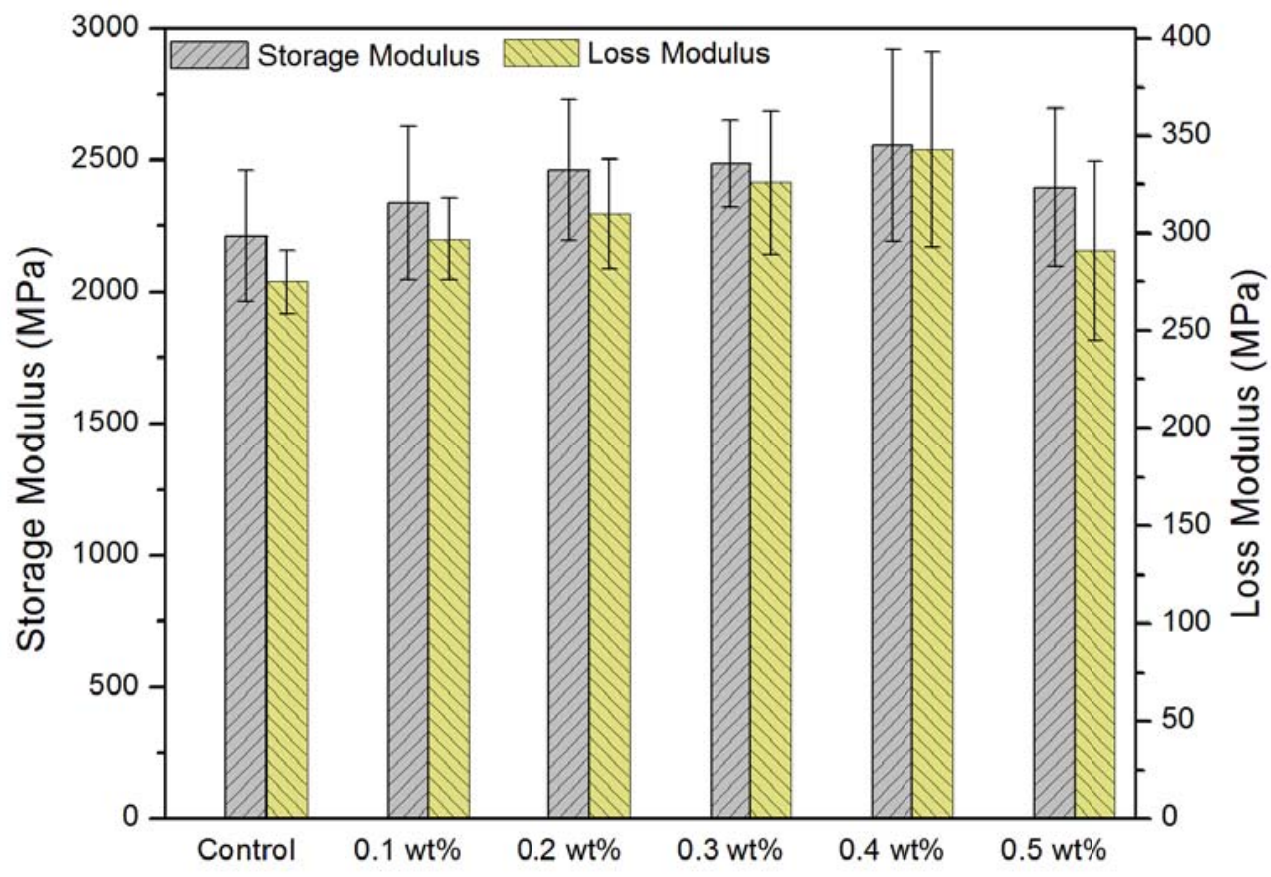

Fig. 6 Comparison of storage and loss modulus of GNP reinforced epoxy with control one.

can be extracted using the peak of tan-delta curve.

Glass transition temperature $\left(\mathrm{T}_{\mathrm{g}}\right)$ for the $0.4 \mathrm{wt} \%$ GNP reinforced composite increased $10 \%$ compared to the control sample. GNP restrict the molecular motion of polymer chains when the temperature increases. Therefore, polymer chains in resin-nanoparticles network start to move at a temperature that is higher than that of the polymer chains of the control resin sample. This in turn results in a high glass transition temperature. 


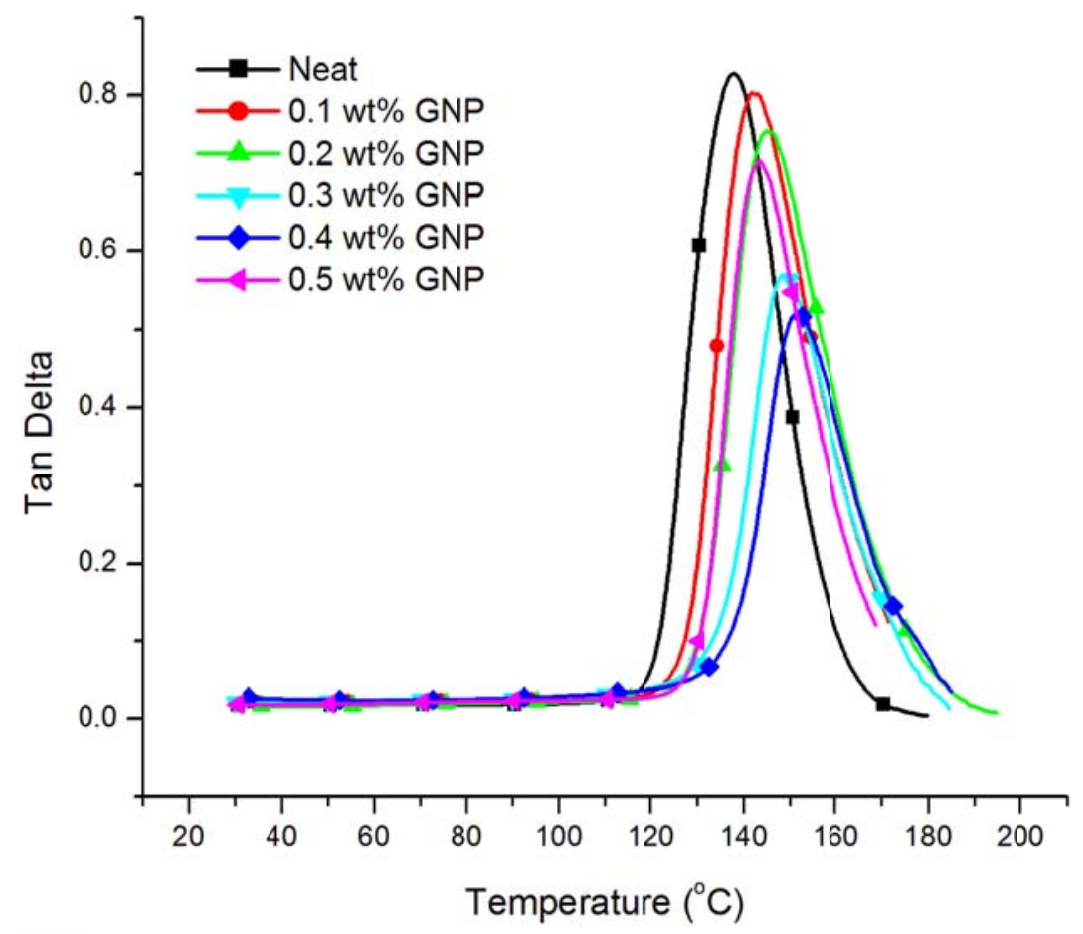

Fig. 7 Tan Delta plot of control and GNP reinforced epoxy nanocomposites.

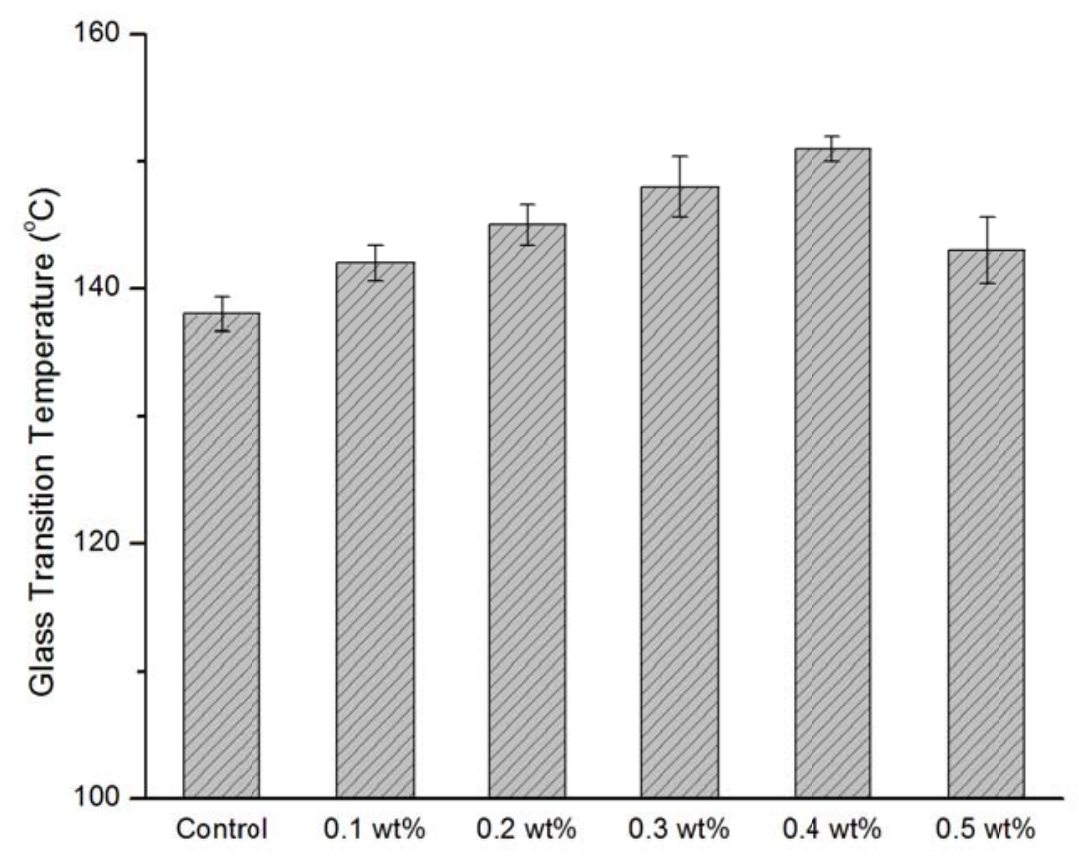

Fig. 8 Comparison of glass transition temperature for GNP reinforced epoxy samples.

Fig. 8 illustrates the variation of $T_{g}$ with respect to the GNP loading. It can be seen thatthe addition of even a small amount of GNP improved the $\mathrm{T}_{\mathrm{g}}$. Without GNP, $\mathrm{T}_{\mathrm{g}}$ of the control system is about $138^{\circ} \mathrm{C}$ while it is observed to be $142,145,148,151$ and $143{ }^{\circ} \mathrm{C}$ for $0.1,0.2,0.3,0.4$ and $0.5 \mathrm{wt} \%$ of GNP reinforced composites, respectively (Table 2).

The rise in $T_{g}$ in the polymeric system is predominantly affected by the amount and dispersion of GNP, degree of crosslinking, and interfacial 
interaction [36, 37]. In our study, the dispersed GNP has inhibited the molecular motion. Therefore, an increase is observed in $T_{g}$. The maximum is seen to be observed in the $0.4 \mathrm{wt} \%$ sample. Further information about mechanical properties of samples and relaxation behavior can be obtained from the height and width of the $\tan \delta$ peaks. The average peak height of $\tan \delta$ curves is measured as $0.82,0.78,0.73,0.54,0.48$ and 0.71 for neat, 0.1, 0.2, 0.3, 0.4 and $0.5 \mathrm{wt} \%$ GNP-loaded samples, respectively. A gradual decrease in the $\tan \delta$ peaks with respect to the concentration of the GNP is observed up to the $0.4 \mathrm{wt} \%$. A lower $\tan \delta$ height points to the reduced mechanical loss because of the lower friction between the molecular chains [37]. The resultant data of DMA are presented in Table 2.

\subsection{Thermomechanical Analysis (TMA)}

Fig. 9 indicates the change of dimension vs. temperature plot for nanocomposites. The coefficient of thermal expansion (CTE) can be obtained using the slope from the plot and initial length of composites. It is obvious from this figure that the expansion of nanocomposites increases with the increase of temperature up to the glass transition temperature. When the transition starts, the nanocomposites transforms from the glassy state to the rubbery state. Therefore, nanocomposites soften and the probe measuring the dimension drops down. A sharp drop of the plot can be observed at onset (start of degradation) of glass transition. The dimension decreases until the

Table 2 DMA results of control and GNP reinforced epoxy nanocomposites.

\begin{tabular}{|c|c|c|c|c|c|c|}
\hline \multirow[b]{2}{*}{ Specimen category } & \multicolumn{6}{|c|}{ Viscoelastic properties of epoxy/GNP nanocomposites } \\
\hline & $\begin{array}{l}\text { Storage modulus } \\
(\mathrm{MPa})\end{array}$ & $\begin{array}{l}\text { \% Change w.r.t } \\
\text { control }\end{array}$ & $\begin{array}{l}\text { Loss modulus } \\
\text { (MPa) }\end{array}$ & $\begin{array}{l}\text { \% Change w.r.t } \\
\text { control }\end{array}$ & $\begin{array}{l}\text { Glass transition } \\
\text { temperature }\left({ }^{\circ} \mathrm{C}\right)\end{array}$ & $\begin{array}{l}\text { \% Change w.r.t } \\
\text { control }\end{array}$ \\
\hline Neat & $2,213 \pm 249$ & & $275 \pm 16$ & & $138 \pm 1.34$ & \\
\hline $0.1 \mathrm{wt} \%$ & $2,336 \pm 292$ & 5.55 & $297 \pm 21$ & 8.00 & $142 \pm 1.43$ & 2.89 \\
\hline $0.2 \mathrm{wt} \%$ & $2,462 \pm 268$ & 11.25 & $310 \pm 28$ & 12.72 & $145 \pm 1.58$ & 5.07 \\
\hline $0.3 \mathrm{wt} \%$ & $2,487 \pm 166$ & 12.38 & $326 \pm 37$ & 18.54 & $148 \pm 2.38$ & 7.24 \\
\hline $0.4 \mathrm{wt} \%$ & $2,557 \pm 364$ & 15.54 & $343 \pm 50$ & 24.72 & $151 \pm 0.96$ & 9.42 \\
\hline $0.5 \mathrm{wt} \%$ & $2,397 \pm 299$ & 8.31 & $291 \pm 46$ & 5.81 & $143 \pm 2.61$ & 3.62 \\
\hline
\end{tabular}

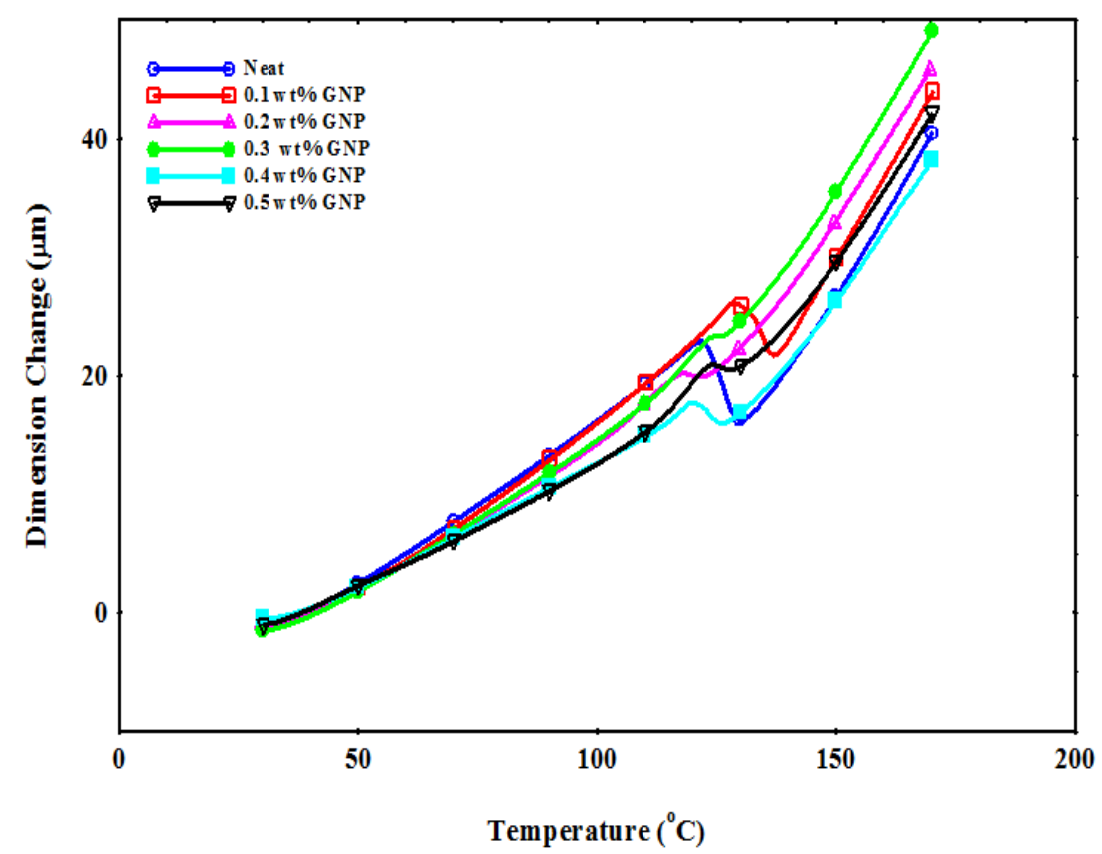

Fig. 9 Dimension change vs. temperature plot for GNP reinforced epoxy samples. 
completion of transition and the nanocomposite becomes rubbery. After that the probe reaches the lowest point. That's the minimum point on the plot. After that, with an increase of the temperature the dimension increases. From these two parts of the plot, that is before and after the glass transition temperature slopes of the plot are measured and from the slope and initial length of composite the CTE can be determined. For most engineering applications of polymeric composites, the CTE is considered as an important thermomechanical property. Most of the polymeric materials have high CTE value which limits their applications. However, an incorporation of a small amount of nanofillers in the polymeric matrix can significantly reduce the overall CTE of the polymer [38]. In order to ensure good dimensional stability, a lower CTE value is desired. Since the GNP has very low CTE [37], it is expected that its presence will considerably influence the CTE of the composite material. Fig. 10 depicts the variation in dimension as a function of the amount of GNP in the temperature range well before and after the glass transition temperature.

In Table 3, a summary is presented on the effect of GNP on the thermal expansion behavior of composites. The average CTE of epoxy composite was measured to be $73.27 \mathrm{ppm} /{ }^{\circ} \mathrm{C}$. The addition of GNP reduced this value and the CTE value for the $0.4 \mathrm{wt} \%$ GNP infused epoxy wasfound to be $37 \%$ less than the sample without GNP. This improvement was possible because of the good dispersability of the GNP into the resin system. As a result, the interfacial characteristics

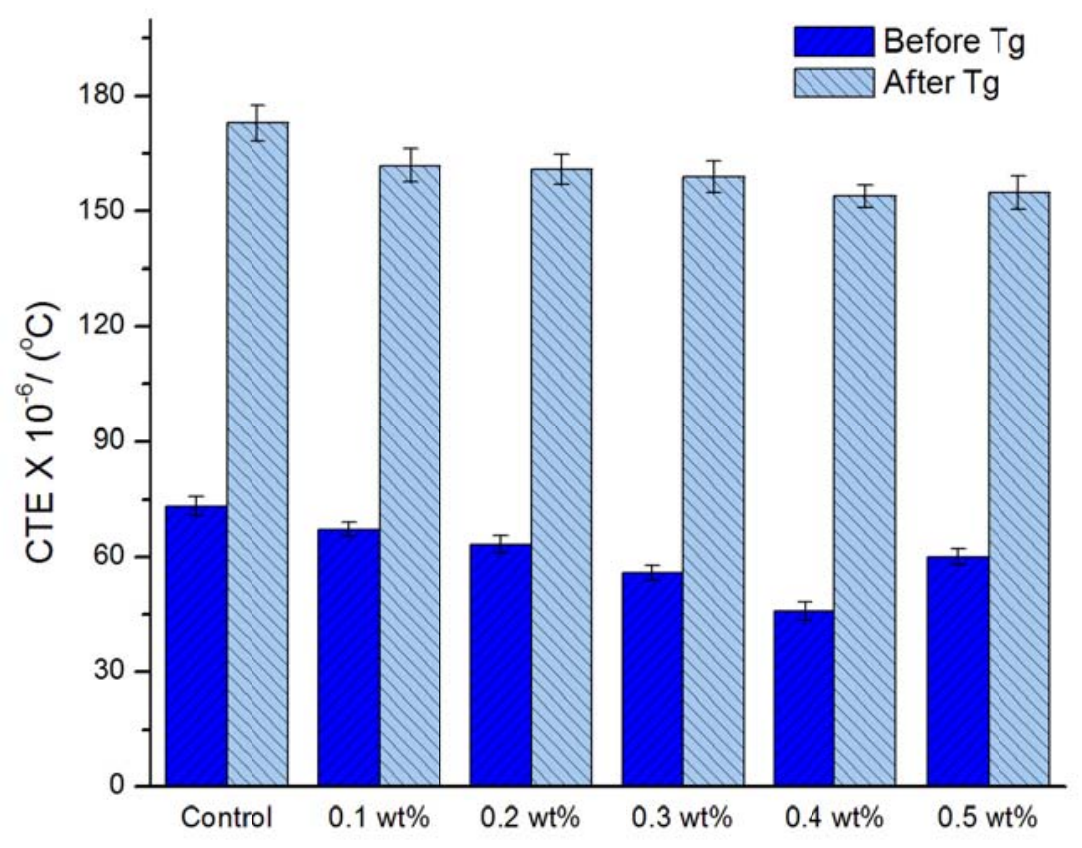

Fig. 10 CTE before and after glass transition temperature for epoxy nanocomposites.

Table 3 TMA results for nanocomposites.

\begin{tabular}{|c|c|c|c|c|}
\hline Specimen category & CTE (before Tg) $\left(\mu \mathrm{m} /\left(\mathrm{m}-{ }^{\circ} \mathrm{C}\right)\right)$ & $\%$ Change w.r.t control & CTE $\left(\right.$ after Tg) $\left(\mu \mathrm{m} /\left(\mathrm{m}-{ }^{\circ} \mathrm{C}\right)\right)$ & $\%$ Change w.r.t control \\
\hline Neat & $73.27 \pm 2.53$ & - & $173 \pm 4.69$ & - \\
\hline $0.1 \mathrm{wt} \%$ & $67.14 \pm 1.85$ & -6.13 & $162 \pm 4.25$ & -6.35 \\
\hline $0.2 \mathrm{wt} \%$ & $63.29 \pm 2.19$ & -13.62 & $161 \pm 3.84$ & -6.93 \\
\hline $0.3 \mathrm{wt} \%$ & $55.74 \pm 1.93$ & -23.92 & $159 \pm 4.13$ & -8.09 \\
\hline $0.4 \mathrm{wt} \%$ & $45.95 \pm 2.41$ & -37.28 & $154 \pm 2.96$ & -10.98 \\
\hline $0.5 \mathrm{wt} \%$ & $60.03 \pm 2.07$ & -22.11 & $155 \pm 4.37$ & -10.4 \\
\hline
\end{tabular}


between the epoxy and the GNP improved. Moreover, well dispersed GNP can align the polymer chain along their axial direction.

Therefore, they can be easily associated with the polymer molecule. This also aids in disallowing the thermally induced movement. However, further addition of GNP $(0.5 \mathrm{wt} \%)$ resulted in a slight increase in the CTE compared to the $0.4 \mathrm{wt} \%$ sample. The higher value of CTE at $0.5 \%$ GNP sample can be explained by the aggregates formed at a loading higher than the normal. Additionally, the presence of nanoparticles becomes less effective to resist the deformation in the rubbery state.

\section{Conclusions}

In this study, an amino functionalized GNP was infused as a nanofiller into EPON 828 epoxy resin system. The incorporation of GNP at very low concentration (up to $0.4 \mathrm{wt} \%$ ) enhanced mechanical, viscoelastic, and thermomechanical properties of the resin. Flexural strength and modulus of the nanocomposite samples increased significantly. The highest enhancement of these two properties was found to be $20 \%$ and $40 \%$, respectively, for the 0.4 wt $\%$ GNP infused samples. SEM micrographs revealed a much rougher fracture surfaces for mechanically tested GNP-loaded samples compared to that of the neat ones due to a strong interfacial interaction of the GNP with the epoxy. The storage modulus was increased by about $16 \%$ for the $0.4 \mathrm{wt} \%$ GNP-loaded sample compared to the neat epoxy. The glass transition temperature and loss modulus were also improved with the addition of GNP. The coefficient of thermal expansion was found to be decreased with an increase of the GNP concentration up to the $0.4 \mathrm{wt} \%$. The maximum reduction observed was about $37 \%$ for the $0.4 \mathrm{wt} \%$ GNP-loaded sample.

\section{Acknowledgments}

The authors acknowledge the Air Force Research Laboratory Munitions Directorate, Eglin AFB, FL
32542, USA for their financial support (Grant No. FA8651-14-1-0001 and FA8651-14-1-0008) to carry out this research work.

\section{References}

[1] Geng,Y., Liu, M. Y., Li, J., Shi, X. M. and Kim, J. K. 2008. "Effects of Surfactant Treatment on Mechanical and Electrical Properties of CNT/Epoxy Nanocomposites." Compos. Part A Appl. Sci. Manuf. 39: 1876-83.

[2] Spitalsky, Z., Tasis, D., Papagelis, K. and Galiotis, C. 2010. "Carbon Nanotube-Polymer Composites: Chemistry, Processing, Mechanical and Electrical Properties." Progress in Polymer Science 35: 357-401.

[3] Hong, C.-E., Lee, J.-H., Kalappa, P. and Advani, S. G. 2007. "Effects of Oxidative Conditions on Properties of Multi-Walled Carbon Nanotubes in Polymer Nanocomposites." Compos. Sci. Technol. 67: 1027-34.

[4] Liu, N., Luo, F., Wu, H., Liu, Y., Zhang, C. and Chen, J. 2008. "One-Step Ionic-Liquid-Assisted Electrochemical Synthesis of Ionic-Liquid-Functionalized Graphene Sheets Directly from Graphite." Adv. Funct. Mater. 18: 1518-25.

[5] Wang, L., Hong, J. and Chen, G. 2010. "Comparison Study of Graphite Nanosheets and Carbon Black as Fillers for High Density Polyethylene.” Polym. Eng. Sci. 50: 2176-81.

[6] Kalaitzidou, K., Fukushima, H. and Drzal, L. T. 2007. “A New Compounding Method for Exfoliated Graphite-Polypropylene Nanocomposites with Enhanced Flexural Properties and Lower Percolation Threshold." Compos. Sci. Technol. 67: 2045-51.

[7] Park, S. and Ruoff, R. S. 2009. "Chemical Methods for the Production of Graphenes." Nat. Nanotechnol. 4: 217-24.

[8] Stankovich, S., Dikin, D. A., Dommett, G. H. B., Kohlhaas, K. M., Zimney, E. J. and Stach, E. A. et al. 2006. "Graphene-Based Composite Materials." Nature 442: 282-6.

[9] Ramanathan, T., Abdala, A. A., Stankovich, S., Dikin, D. A., Herrera-Alonso, M. and Piner, R. D. et al. 2008. "Functionalized Graphene Sheets for Polymer Nanocomposites." Nat. Nanotechnol. 3: 327-31.

[10] Eda, G. and Chhowalla, M. 2009. "Graphene-Based Composite Thin Films for Electronics." Nano Lett. 9: 814-8.

[11] Liang, J.-J., Xu, Y.-F. Huang, Y., Zhang, L., Wang, Y. and Ma, Y.-F. et al. 2009. "Infrared-Triggered Actuators from Graphene-Based Nanocomposites.” J. Phys. Chem. C 113: 9921-7.

[12] Liang, J., Huang, Y., Zhang, L., Wang, Y., Ma, Y. and 
Cuo, T. et al. 2009. "Molecular-Level Dispersion of Graphene into Poly(vinyl Alcohol) and Effective Reinforcement of their Nanocomposites." Adv. Funct. Mater. 19: 2297-302.

[13] Lee, C., Wei, X., Kysar, J. W. and Hone, J. 2008. "Measurement of the Elastic Properties and Intrinsic Strength of Monolayer Graphene." Science 321: 385-8.

[14] Van, L. G., Van, A. C., Van, D. V and Geerlings, P. 2000. "Ab Initio Study of the Elastic Properties of Single-Walled Carbon Nanotubes and Graphene." Chem. Phys. Lett. 326: 181-5.

[15] Rafiee, M. A., Rafiee, J., Wang, Z., Song, H., Yu, Z. Z. and Koratkar, N. 2009. "Enhanced Mechanical Properties of Nanocomposites at Low Graphene Content." ACS Nano 3: 3884-90.

[16] Yasmin, A. and Daniel, I. M. 2004. "Mechanical and Thermal Properties of Graphite Platelet/Epoxy Composites." Polymer 45: 8211-9.

[17] Yasmin, A., Luo, J. J. and Daniel, I. M. 2006. "Processing of Expanded Graphite Reinforced Polymer Nanocomposites." Compos. Sci. Technol. 66: 1179-86.

[18] Chandrasekaran, S., Seidel, C. and Schulte, K. 2013. "Preparation and Characterization of Graphite Nano-Platelet (GNP)/Epoxy Nano-Composite: Mechanical, Electrical and Thermal Properties." Eur. Polym. J. 49: 3878-88.

[19] Fang, M., Zhang, Z., Li, J., Zhang, H., Lu, H. and Yang, Y. 2010. "Constructing Hierarchically Structured Interphases for Strong and Tough Epoxy Nanocomposites by Amine-Rich Graphene Surfaces." Journal of Materials Chemistry 20: 9635.

[20] Wang, X., Xing, W., Zhang, P., Song, L., Yang, H. and Hu, Y. 2012. "Covalent Functionalization of Graphene with Organosilane and its Use as a Reinforcement in Epoxy Composites." Compos. Sci. Technol. 72: 737-43.

[21] Ma, P. C., Mo, S. Y., Tang, B. Z. and Kim, J. K. 2010. "Dispersion, Interfacial Interaction and Re-Agglomeration of Functionalized Carbon Nanotubes in Epoxy Composites." Carbon 48: 1824-34.

[22] Shen, J., Huang, W., Wu, L., Hu, Y. and Ye, M. 2007. "The Reinforcement Role of Different Amino-Functionalized Multi-Walled Carbon Nanotubes in Epoxy Nanocomposites." Compos. Sci. Technol. 67: 3041-50.

[23] Gojny, F., Wichmann, M., Fielder, B. and Schutle, K. 2005. "Influence of Different Carbon Nanotubes on the Mechanical Properties of Epoxy Matrix Composites - A Comparative Study." Compos. Sci. Technol. 65: 2300-13.

[24] Liang, J., Wang, Y., Huang, Y., Ma, Y., Liu, Z. and Cai, J. et al. 2009. "Electromagnetic Interference Shielding of Graphene/Epoxy Composites.” Carbon 47 (3): 922-5.
[25] Kim, H., Miura, Y. and Macosko, C. W. 2010. "Graphene/Polyurethane Nanocomposites for Improved Gas Barrier and Electrical Conductivity." Chem Mater 22 (11): 3441-50.

[26] Ghosh, S., Calizo, I., Teweldebrhan, D., Pokatilov, E. P., Nika, D. L. and Balandin, A. A. et al. 2008. "Extremely High Thermal Conductivity of Graphene: Prospects for Thermal Management Applications in Nanoelectronic Circuits." Appl Phys Lett 92 (15): 151911-3.

[27] Kai, W. H., Hirota, Y., Hua, L. and Inoue, Y. 2008. "Thermal and Mechanical Properties of a Poly (ع-Caprolactone)/Graphite Oxide Composite.” J Appl Polym Sci 107 (3): 1395-400.

[28] Inuwa, I. M., Hassan, A., Samsudin, S. A., Kassim, M. H. M. and Jawaid, M. 2014. "Mechanical and Thermal Properties of Exfoliated Graphite Nanoplatelets Reinforced Polyethylene Terephthalate/Polypropylene Composites." Polym Compos 35 (10): 2029-35.

[29] Wang, J. C., Wang, X. B., Xu, C. H., Zhang, M. and Shang, X. P. 2011. "Preparation of Graphene/Poly (Vinyl Alcohol) Nanocomposites with Enhanced Mechanical Properties and Water Resistance." Polym Int. 60 (5): 816-22.

[30] Liang, J., Huang, Y., Zhang, L., Wang, Y., Ma, Y. and Guo, T. et al. 2009. "Molecular-Level Dispersion of Graphene into Poly (Vinyl Alcohol) and Effective Reinforcement of their Nanocomposites." Adv Funct Mater 19 (14): 2297-302.

[31] Huang, G., Gao, J., Wang, X., Liang, H. and Ge, C. 2012. "How Can Graphene Reduce the Flammability of Polymer Nanocomposites." Mater Lett 66: 187-9.

[32] Han, Y., Wu, Y., Shen, M., Huang, X., Zhu, J. and Zhang, X. 2013. "Preparation and Properties of Polystyrene Nanocomposites with Graphite Oxide and Graphene as Flame Retardants." J Mater Sci 48: 4214-22.

[33] Liu, S., Yan, H., Fang, Z. and Wang, H. 2014. "Effect of Graphene Nanosheets on Morphology, Thermal Stability and Flame Retardancy of Epoxy Resin." Compos Sci Technol 90: 40-7.

[34] Rahman, M. M., Zainuddin, S., Hosur, M. V., Malone, J. E., Salam, M. B. A. and Kumar, A. et al. 2012. "Improvements in Mechanical and Thermo-Mechanical Properties of E-Glass/Epoxy Composites Using Amino Functionalized MWCNTs." Composite Structures 94: 2397-406

[35] Zhang, A. Y., Li, D. H., Zhang, D. X., Lu, H. B., Xiao, H. Y. and Jia, J. 2011. "Qualitative Separation of the Effect of Voids on the Static Mechanical Properties of Hygrothermally Conditioned Carbon/Epoxy Composites.' Express Polym. Lett. 5: 708-16.

[36] Abdalla, M., Dean, D., Adibempe, D., Nyairo, E., Robinson, P. and Thompson, G. 2007. "The Effect of 
Interfacial Chemistry on Molecular Mobility and Morphology of Multiwalled Carbon Nanotubes Epoxy Nanocomposite." Polymer 48: 5662-70.

[37] Ganguli, S., Roy, A. K. and Anderson, D. P. 2008. "Improved Thermal Conductivity for Chemically Functionalized Exfoliated Graphite/Epoxy Composites."
Carbon 46: 806-17.

[38] Godara, A., Mezzo, L., Luizi, F., Warrier, A., Lomov, S. V. and Vuure, van A. W. et al. 2009. "Influence of Carbon Nanotube Reinforcement on the Processing and the Mechanical Behaviour of Carbon Fiber/Epoxy Composites." Carbon 47: 2914-23. 